\title{
Historical development of water-powered mechanical clocks
}

\author{
Zheng-Hui Hwang ${ }^{1}$, Hong-Sen Yan ${ }^{1}$, and Tsung-Yi Lin ${ }^{2}$ \\ ${ }^{1}$ Department of Mechanical Engineering, National Cheng Kung University, \\ Tainan 70101, Taiwan \\ ${ }^{2}$ Department of Mechanical Engineering, Southern Taiwan University \\ of Science Technology, Tainan 71005, Taiwan \\ Correspondence: Zheng-Hui Hwang (pmew070010604@gmail.com)
}

Received: 16 November 2020 - Revised: 30 December 2020 - Accepted: 5 January 2021 - Published: 19 February 2021

Abstract. This article examines the historical development of ancient water-powered mechanical clocks. The study begins with a comprehensive analysis and comparison of the different types of ancient clepsydra, their use and development and the development of their feedback systems, power systems, and time-reporting systems. Before becoming mechanized, water clocks (clepsydra) were mainly used for astronomical timekeeping, during religious sacrifices, for military affairs, court litigation timekeeping, and the time allocation of water rights. The invention of the feedback system in the 3rd century before common era (BCE) opened the door to the mechanization of water clocks. The float is the earliest power-driven element. In the 8th century, the emergence of waterwheels with timing functions in water-powered mechanical clocks prompted ancient China to develop water-powered mechanical clocks with waterwheel steelyard clepsydra devices, time-reporting devices, astronomical demonstration devices, and multiple time-reporting wooden pavilions. After the 13th century, mechanical clocks started to integrate elements from Chinese and Western cultures. In addition to the development of new styles of water-powered mechanical clocks in ancient China, the Western mercury wheels with timing functions evolved into compartmented cylindrical mercury clocks.

\section{Introduction}

In ancient times, human observed changes in the Sun and Moon and developed the system of the calendar to help advance agriculture. Keeping track of the shadow of the Sun may be regarded as one of the earliest methods of timekeeping; by observing the length of the Sun's shadow in order to determine the Sun's position in the ecliptic, a system for timekeeping was developed. During nighttime, humans observed the cycle of the movement of the stars and used water clocks as timekeeping instruments (Breasted, 1935). A water clock, or clepsydra, is a timepiece with which time is measured by regulating the flow of water (sometimes mercury) into or out of a vessel, or a clepsydra, and observing the changes in the amount of water (or mercury) in the vessel (Hua, 1991). A water clock may be one of either the following six types: outflowing type, simple inflowing type, sinking bowl type, polyvascular type, inflow clepsydra with overflow tank type (Goodenow et al., 2015), and steelyard clepsydra (Lin, 2001). The water clock was referred to by several names in ancient times. During the ancient Babylonian period, maltaktum was a word that had been interpreted to mean water clock (Brown et al., 1999), while in ancient Egypt, the hieroglyph hinu was used for clepsydra, and Alan Henderson Gardiner (an Egyptologist, linguist, philologist, and independent scholar) listed the pictograms of nu pot for bronze timekeeping instruments for short intervals (Neugebauer, 1947). In ancient Greece, the term clepsydra was used to represent the water clock (Vodolazhskaya et al., 2015), and in ancient China, the term lou ke was used. As for the origin of the water clock (clepsydra), there is a branch of literature that attributes its invention to the Egyptian astronomer Amendmenhet (Panou et al., 2014), while according to other ancient Chinese historical documents, the clepsydra was in- 
vented by the Yellow Emperor (2717-2599 before common era-BCE; Wei et al., 1973).

The coefficient of the viscosity of water changes with temperature and affects the speed of the flow of water. During the Ptolemaic dynasty in Egypt, the ancient Greek mechanical engineer Ctesibius (285-222 BCE) developed the principle of feedback control, which opened the door to the mechanization of water clocks (Drachmann, 1976). The West developed water-powered mechanical clocks with a float as a power input element, a rope hammer as a transmission system, and a time-reporting and time-showing system. Zhang Heng (78-139 common era - CE), during the eastern Han dynasty, built a water-powered celestial globe. After the 8th century, ancient China began to develop water-powered mechanical clocks with waterwheels as the driving element. Later, water-powered mechanical clocks with a waterwheel steelyard clepsydra device, a time-reporting mechanism, an astronomical demonstration device, and a multi-storey timereporting and time-showing pavilion were invented. Looking at ancient developments, water-powered mechanical clocks can be divided into three categories, namely those that were water-powered, those that included time-reporting mechanisms, and those without astronomical instruments (Lin, 2001).

Because data on Western water-powered mechanical clocks are scattered and difficult to collect, historical records of ancient Chinese water-powered mechanical astronomical clocks are relatively simple, and because there are no historical records on the development of water-powered astronomical clocks in China, it is not clear how a clepsydra was able to drive a water-powered astronomical clock and trigger a timereporting mechanism. In addition, apart from studies on the waterwheel steelyard clepsydra clock tower built by Su Song (1020-1101 CE) during the northern Song dynasty, there has been a lack of in-depth studies and work on water-powered astronomical clocks to replicate the original system. As a result, the mechanical structures and mode of energy transfer involved cannot be understood in full.

This work aims to study the different types of ancient clepsydras and the evolution of their use, feedback control systems, and energy transfer systems; this work also explores the development of the time display and time-reporting systems. A systematic study, analysis, and comparison are carried out so as to identify the requirements necessary to reconstruct the original design of a water-powered mechanical clock, which in turn could be used as a basis for a systematic, restorative study of water-powered astronomical clocks.

\section{Types and uses of clepsydras}

To develop agriculture, the Sumerians and Babylonians in Mesopotamia (4000-3000 BCE) developed calendar systems, timekeeping, and methods to predict the future. They used sundials and water clocks and observed the movement

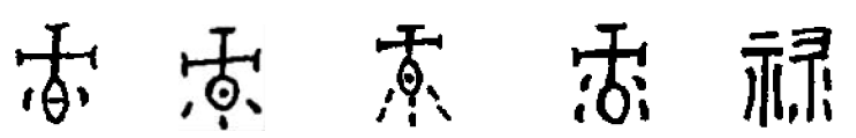

Figure 1. Oracle bone script and bronze script for the hieroglyphs (Zou, 2007).

of stars to keep time. By observing the complete artifacts and fragments of ancient water clocks that have been kept to date, scholars concluded that water clocks built at the time were simple outflow clepsydras (Brown et al., 1999). In 1904, the Karnak clepsydra, a pot-shaped outflow clepsydra was unearthed at the temple of Amun-Re at Karnak in ancient Egypt. Archeologists subsequently confirmed that the clepsydra dated back to the reign of Amenhotep III (1391$1353 \mathrm{BCE})$, and that it was used in the temple to keep time during religious ceremonies (Pogo, 1936), to measure the length of the night, and as an astrological timing tool.

The Hindu book Vedanga jyotisha (Sarma, 2018) records that the earliest ancient Indian clepsydra in the 5th and 6th centuries BCE was a straight outflow clepsydra. In 400 BCE, sinking bowl clepsydras replaced the outflowing-type clepsydras. The sinking bowl clepsydra consisted of a semicircular copper bowl with a tiny hole at the bottom. The time required for a float to sink to the bottom of the bowl was $24 \mathrm{~min}$, and the process could be repeated 60 times in a day (Sarma, 1994). In ancient India, scientists used this type of clepsydra for astronomical demonstrations, fortune-telling, and for keeping time during irrigation (Aubriot, 2018; Sridhar and Shivakumar, 2014). This type of clepsydra was used as early as about $500 \mathrm{BCE}$ and was used by the ancient Persians as the water right of qanat (Bonine, 1982) and as a timing tool for the court in ancient Rome to question prisoners (McNown, 1976).

In ancient China, historical records show that the clepsydra was invented by the Yellow Emperor (2711-2598 BCE) or Huangdi. The Chinese character 彔 is a hieroglyph that refers to water clocks. Figure 1 (Zou, 2007) shows the oracle bone script, which is the earliest known form of Chinese writing, and the bronze script for the hieroglyph 彔. The hieroglyph 彔 refers to the water-drawing mechanism by the well, including a pulley, rope, and a water-drawing device, which is perhaps the most primitive outflowing type of clepsydra in ancient China.

During the Shang dynasty (1600-1040 BCE), the biao, an ancient solar shadow measuring instrument, and the clepsydra were used to observe stars and for timekeeping at night. In this period, time was kept using the unit of measurement $\mathrm{Ke}$, which represented one-hundredth of a day. Ke, which literally means mark, referred to the scale markings on clepsydras that were used to keep time. Because the clepsydra was able to take measurements at equal intervals, a day could then be divided into 100 such intervals, which subsequently led to the invention of the Ke system of measurement and of 
the qian chi (indicator arrow; Chen and Hua, 2007) and lou ke, which were mainly used for military and funeral shifts, etc., and timekeeping was done using the arrow submersion method (Hua, 1991). From 1958 to 1977, the types of clepsydra unearthed included a single-pot drain-type sinker, a floating arrow for the kettle, and a floating arrow clutter.

During the western Han dynasty, Emperor Wu (157$87 \mathrm{BCE})$, in his attempt to improve the calendar system, accurately measured the movement of the stars, which paved the way for more accurate measurements on the clepsydra. Because differences in the water level of the sinking arrow clepsydra would result in uneven speed of water flow, clepsydras built prior to Emperor Wu were single-vessel outflowing clepsydras. It is likely that invention of the floating arrow clepsydra came after the reign of Emperor $\mathrm{Wu}$, and that such clepsydras were of the simple inflowing type. In the West, it is likely that both the simple inflowing type and the inflowing type with overflow tank clepsydras appeared during the 3rd century BCE. Scholars believe that, in order to stabilize the water level of the water clock, the ancient Greek scientist Ctesibius might have used the abovementioned two types of clepsydras to design his water clocks (Drachmann, 1976). During the kingdom of Macedonia (808-168 BCE), the inflow type with an overflow tank clepsydra was first used by the ancient Greek astronomer Andronicus of Cyrrhus (about 100-200 BCE) in his Tower of the winds (Noble and de Solla Price, 1968). In ancient China, Yan Su (961-1040 CE), during the northern Song dynasty, used the inflow type with an overflow tank to design a lian hua lou (lotus clepsydra; Hua, 1991).

In ancient China, starting from the period of Zhang Heng (78-139 CE) during the eastern Han dynasty, twolevel floating-arrow clepsydra were used to drive the water transport celestial globe. In the following dynasties, in order to maintain a constant water level in the vessel, the number of draining vessels was increased, which eventually led to the development of polyvascular-type clepsydras. During the Tang dynasty, Japan sent students to China to study timekeeping and clepsydras (Nam, 1995), and during the Heian period (795-1185 CE), multi-level clepsydras were used to measure time. Nihon shoki, a book written by Prince Toneri (681-720 CE) and others, was the earliest document that recorded the use of rokoku (clepsydras) in Japan. On the other hand, during the Three Kingdoms (37 BCE-935 CE), the Korean Peninsula acquired ancient astronomical know-how from China, and by the Baekje period (18 BCE-660 CE), clepsydra and timekeeping scholars taught ancient Chinese astronomical know-how to students in Japan. During the reign of Emperor Shun in the Yuan dynasty (1320-1370 CE), officials, scholars, technicians, businesspeople, and Muslims from the Korean Peninsula frequented China, and the interactions led to the flow of technology from the Yuan dynasty and the Muslims to the Korean Peninsula (Nam, 2014).
The cheng lou, or steelyard clepsydra, is a balancing clepsydra and was used in water clocks in the West in ancient times. In chronological order, records of its use include the following: an escapement mechanism as part of a washstand automaton water clock designed by Philo of Byzantium (280-220 BCE; Buick, 2014), a water clock used to control the flow of wine (Woodcroft, 1851) by Hero of Alexandria (10-70 CE) in the Roman province of Egypt, and the tipping bucket in peacock fountains and other automata designed by the Muslim Arab polymath Al-Jazari (1136-1206 CE) during the Artuqid dynasty (Hill, 1973).

The cheng lou in ancient China was invented by Li Lan in the Sui dynasty (581-619 CE), which was used for keeping time in the field and during military ceremonies (Hua, 1991). Furthermore, Xin yi xiang fa yao (New design for an armillary sphere and celestial globe) by Su Song (1020-1101 CE) during the northern Song dynasty also recorded that the escapement regulator used in the shui yun yi xiang tai, or the water-powered armillary sphere and celestial globe, was also a cheng lou mechanism.

In ancient China, short-distance timing devices were used on merchant ships to measure time (Han, 2002) and to measure a person's pulse (Chen and Hua, 2007). In ancient Greece, small clepsydras were used in court as stopwatches to keep the time of court proceedings (Young, 1939), to measure a person's pulse (Pearce, 1939), to keep time in brothels (Ebiesuwa et al., 2013), and to keep time during theatrical performances (James and Thorpe, 1995). The ancient Romans learned from ancient Greece about the use of the sundial and water clock. In $158 \mathrm{BCE}$, the Roman politician Scipio Nasica built a public clepsydra and used clepsydras to keep time in the military during nighttime and to keep time during races and during court proceedings (Ker, 2009). Figure $2 \mathrm{a}-\mathrm{f}$ show examples of each of these six types of clepsydra.

\section{Feedback control and power transfer mechanisms}

The invention of the feedback system promoted the mechanization of the water clock. The water-powered mechanical clock of Ctesibius uses a float as the power drive system and uses a sundial to correct the water flow rate of the flow control valve to improve the accuracy of the water clock (Rose, 1867). The float is the earliest power-driven system of water-powered mechanical clocks. Arab scientists, inheriting the scientific knowledge of ancient Greece, used floats as a power-driven system and combined the concept of a feedback system to design water-powered mechanical clocks with multiple timekeeping. After the 8th century, Yi Xing (683-727 CE) and Liang Lingzhan of the Tang dynasty invented a waterwheel with a timing function (Liu et al., 1981). This changed the drive mode, transmission system, and time-reporting mechanism of the water-powered mechanical clock. They also worked out how to improve the 


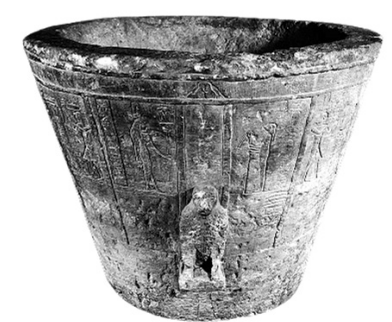

(a) Outflow clepsydra (Ritner, 2016)

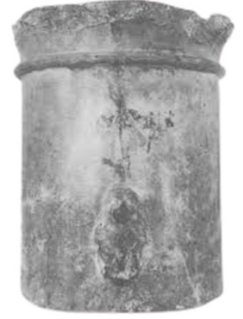

(b) Inflow clepsydra (Sloley, 1993) (c) Sinking bowl clepsydra (Aubriot, 2018)

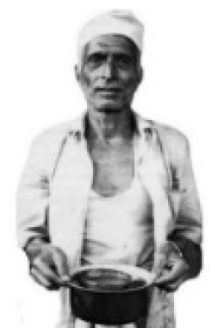

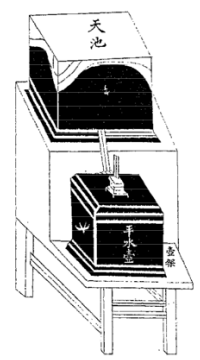

(d) Polyvascular clepsydra (Hu, 1997) (e) Inflow type with overflow tank clepsydra (Chen, 1934)

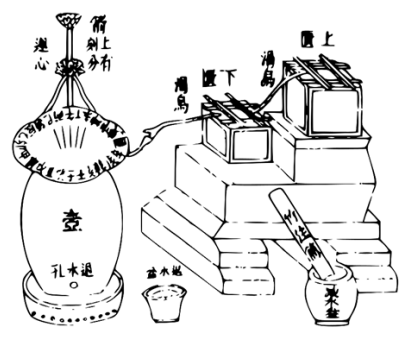

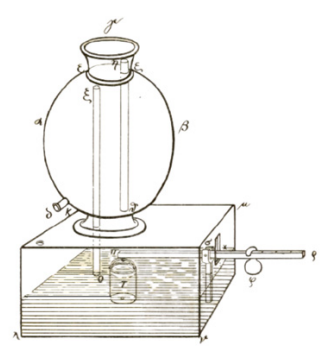

(f) Heron's water clock (steelyard clepsydra) (Schmidt, 1899)

Figure 2. Examples of the six types of clepsydra.

problem of the uneven flow velocity of water-powered mechanical clocks, and thus, improving the accuracy of waterpowered mechanical clocks became the goal of ancient scientists. The following explores the historical evolution of the feedback system and driven system of ancient water-powered mechanical clocks.

\subsection{Feedback control systems}

Before the invention of feedback systems, the sundial was used to correct the accuracy of the water clock (clepsydra) in ancient times. For instance, there are 12 notch lines inside the clepsydra of a Karnak clepsydra (1379-1342 BCE) and the Oriental Institute Museum (OIM) clepsydra (E16875); these notch lines appear to have been used for calibration with the sundial to adjust the monthly water flow rate (Fig. 3). After Ctesibius invented the feedback control system, the feedback principle was applied to water clocks in the form of flow regulating valves, using the siphon effect to regulate water flow in multi-level compensating floating arrow regulating systems. The different methods are explained below.

\subsubsection{Flow regulating valve}

Ancient Greek and Arab scientists applied the principle of feedback to their mechanical devices (Rose, 1867). During the Abbasid Caliphate dynasty, Kitab al-hiyal (The book of ingenious devices) by the Banū Mūsā brothers (803-737 CE) recorded 20 flow regulators that use wedge-shaped float valves to feed animals and supply drinking water (Mayr, 1969). In The work of Archimedes on the building of clocks, attributed to Pseudo-Archimedes, there is a description of a water clock design that features a flow regulator that varied the water temperature based on the month of the year (Mayr, 1969). Later, during the Ayyubid dynasty (1171-1341 CE), Ibn Al-Saati and Al-Jazari designed their water-powered mechanical clocks, taking into account the flow control valve of Pseudo-Archimedes (Fig. 4).

\subsubsection{Siphon effect}

In ancient Greece, Hero of Alexandria developed the adjustable siphon, which could adjust the speed of water drainage by slightly adjusting the height difference between the two ends of the chamber (Drachmann, 1976). In ancient China, during the northern and southern dynasties, Fan Ye (398-445 CE), in the volume of Zhang rang zhuan in Houhan shu (Book of the latter Han), recorded the use of the siphon effect in daily life (Hua, 1991). In addition, the book Chuxue ji, during the Tang dynasty (618-907 CE) also recorded the earliest application of the siphon effect, which was in a clepsydra built by Li Lan during the Sui dynasty (Xu et al., 1976).

\subsubsection{Multi-level compensating floating arrow regulating systems}

Chuxue ji records the earliest origin of a multi-stage compensation floating arrow. This design mainly includes two parts, namely the time display system and the speed control system (Fig. 5; Chen, 1934). The speed control system is mainly used to adjust the water flow rate of each vessel and maintain the uniformity of the water surface of each section. The water surface of the rear vessel is difficult to adjust, 


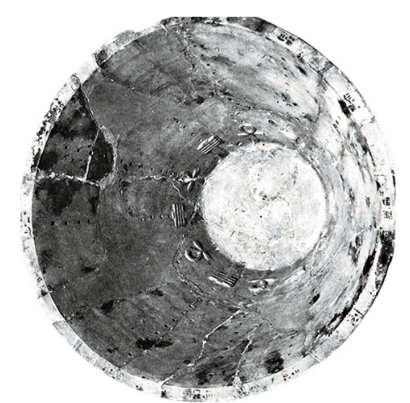

(a) Karnak clepsydra (Anettle, 2018)

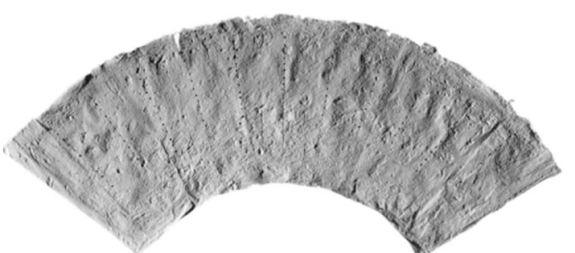

(b) OIME 16785 Clepsydra (Ritner, 2016)

Figure 3. Clepsydra with notch lines showing the regulation flow.

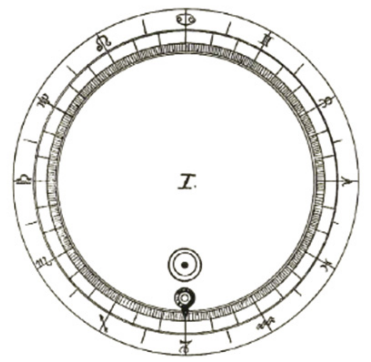

(a) Marcus Vitruvius Pollio's design (80-25 B.C.) (Wellbrock, 2015)

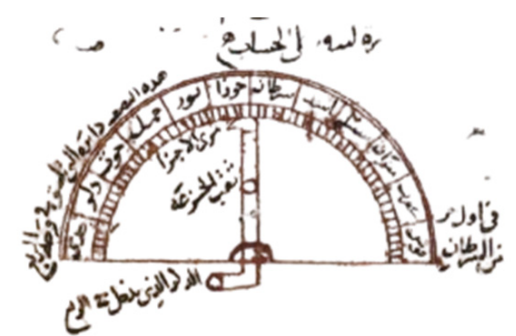

(b) Pseudo Archimedes's design (Wellbrock, 2015)

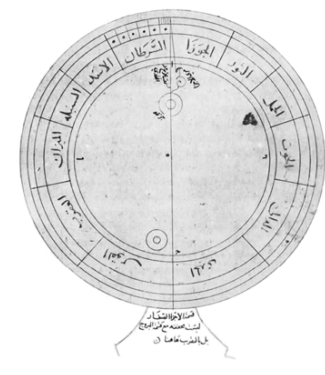

(c) Al-Jazari`s design (1136-1206) (Hill, 1973)

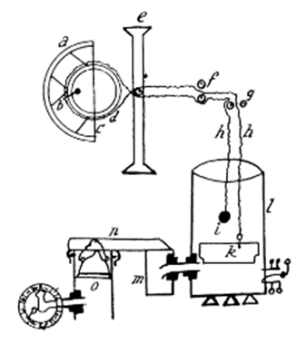

(d) Ibn al-Saati's design (?-1230) (Mayr, 1969)

Figure 4. The Western designs of flow control valve.

which affects the timing accuracy. It was not until the northern Song dynasty that Yan Su (961-1040 CE) invented the overflow two-level clepsydra to make lian hua lou (the lotus clepsydra). The number of vessels is maintained at two as a standard type.

\subsection{Power transmission systems}

In ancient times, power transmission systems of waterpowered mechanical clocks included the use of floats and waterwheels, and they are explained as follows.

\subsubsection{Power transmission using floats}

The water clock of Ctesibius uses a float as a power transmission element to drive the water clock (Sleeswyk and Hulden, 1991). There are two types; one is a float combined with a heavy hammer and a rotating time disc, and the other is a floating arrow type for water clock power transmission. Ancient Greek scientists combined the principles of mechanics and aerodynamics with rope and pulley mechanisms to invent many automated devices. In the Middle Ages (476-1453 CE), Arab scientists, deeply influenced by ancient Greek science, used floats and rope hammers as the power system to design many water-powered mechanical clocks. Al-Jazari's book, entitled The book of knowledge of inge- 


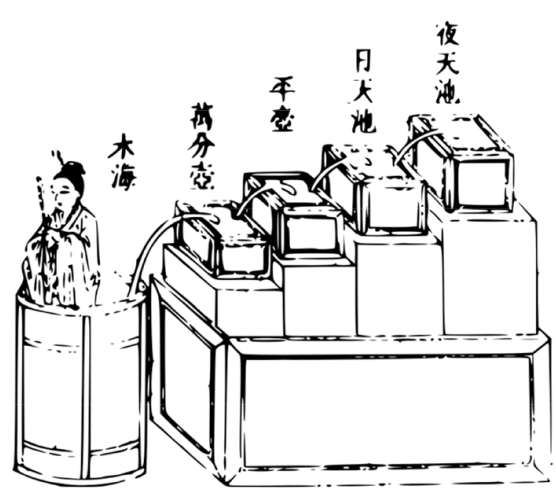

(a) Lu cai's lou ke in the Tang Dynastry (Chen, 1934)

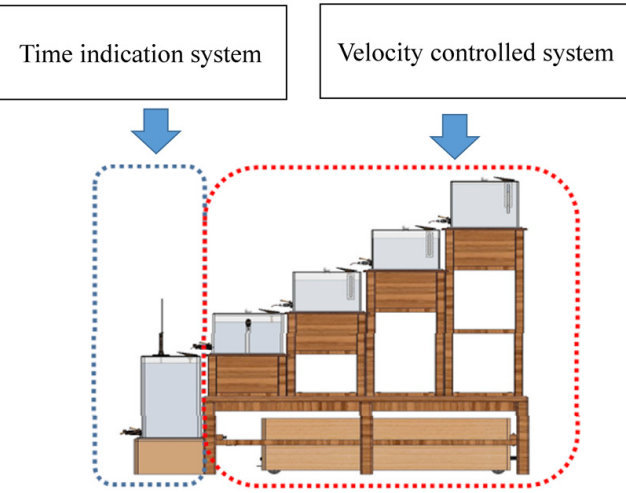

(b) Reconstruction of work $(\mathrm{Xu}, 2015)$

Figure 5. Time indication and speed control system of a multi-stage clepsydra.

nious mechanical devices, recorded that the castle clock used floats, ropes, and heavy hammers as the power transmission system to drive its internal devices. Figure 6 presents the power transmission system device, which consists of a planar mechanism with 10 members and 13 joints with 1 degree of freedom.

In addition, during the Gupta dynasty, the ancient Indian astronomer Āryabhaa (476-550 CE) used floats as a driving force to drive the movement of the wooden celestial globes. The mechanical device of this type of water-powered mechanical clock consists of a planar mechanism with 1 degree of freedom (Fig. 7; Sarma, 2018).

In ancient China, there was no record to show that the float was used as the driving element of the water-powered mechanical clock. However, during the reign of Emperor Wu in the Han dynasty (202 BCE-220 CE), there was a floating arrow, and it was widely used in daily life. Therefore, the float was used as the power-driven element of ancient Chinese water-powered mechanical clocks before the 8th century. In addition, the Records of Sejong of the Joseon dynasty recorded Jiang Young Sil's (1383-1450 CE) striking palace clepsydra (jagyeok-gung-nu), which was a waterpowered mechanical clock that used floating arrows to trigger the timekeeping mechanism. Nam Moon Hyun believes that Jiang Ying Shi's striking palace clepsydra was designed with reference to Yuan Shun's palace clepsydra (Ceccarelli and Koetsier, 2007), and the power transmission element of Yuan Shun's palace clepsydra appeared to be the floating arrow.

\subsubsection{Power transmission using waterwheels}

In the 8th century, waterwheels with timing functions were developed for water-powered mechanical clocks. Monk Yi Xing and Liang Lingzhan's shui yun hun xiang appeared to be the first mechanical clock equipped with a waterwheel that had a timing function. The waterwheel steelyard clepsydra devices is a device that enables the water- wheel to have a timing function. It is composed of a steelyard clepsydra time device and a waterwheel escapement device, which is similar to the escapement of a mechanical clock. For this reason, the waterwheel steelyard clepsydra device is also called the escapement regulator device.

After Yi Xing and Liang Lingzhan during the Tang dynasty, Zhang Si Xun, Su Song (1020-1101 CE), and Wang Wei (1079-1126 CE) of the northern Song dynasty worked to developed the waterwheel steelyard clepsydra device, and they used it in their design of water-powered mechanical clocks. Illustrations of the structure of the waterwheel steelyard clepsydra device can be found in Su Song's Xin yi xiang fa yao (1094-1096 CE) in the northern Song dynasty (Fig. 8; Hu, 1997).

Figure 9 shows the kinematic model of Su Song's waterwheel steelyard clepsydra device with a double-feedback control system; one is the volume feedback control, and the other is the velocity feedback control. The volume feedback control is a force feedback control that uses a lower balancing lever mechanism as a weight comparator to determine whether the upper stopping device has enough power to drive the wheel. The velocity feedback control adjusts the flow rate of the water-receiving scoop to control the periodic frequency of the steelyard clepsydra. Consequently, the waterwheel steelyard clepsydra device can maintain precise timings and regular movements (Lin, 2001).

In the 13th century, the Arab scientist Al-Jazari invented a ratchet mechanism with a timing function and used it in his peacock clock, which was similar to the ancient Chinese waterwheel steelyard clepsydra device (Hill, 1973). This device consists of a planar mechanism with seven members and 11 joints with 1 degree of freedom (Fig. 10).

In addition, Brahmasphutasiddhānta, the treatise on ancient Indian astronomy by Indian mathematician and astronomer Brahmagupta (598-668 CE), contained records of a mercury wheel built by Brahmagupta, which is one of the earliest documented perpetual motion wheels in India. During the 12th century, the concept of perpetual motion ma- 


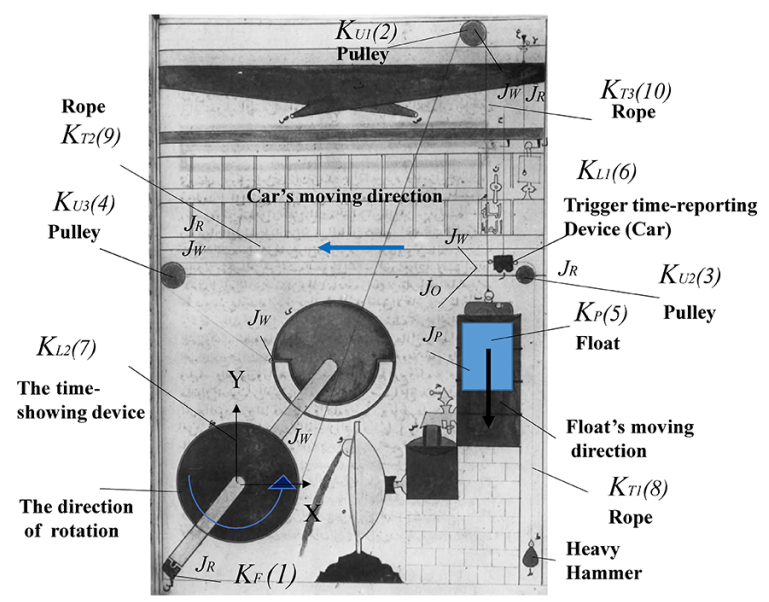

(a) Original illustration (Hill, 1973)

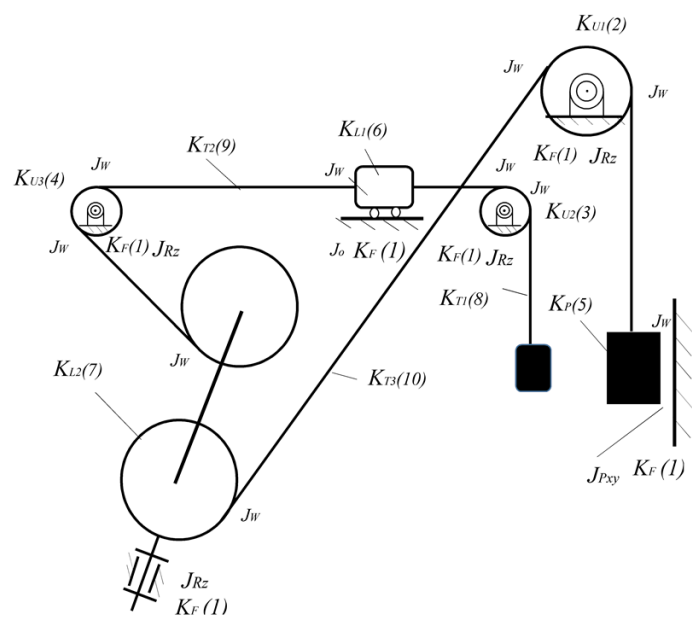

(b) Structural sketch

Figure 6. Power transmission system of Al-Jazari's castle clock.

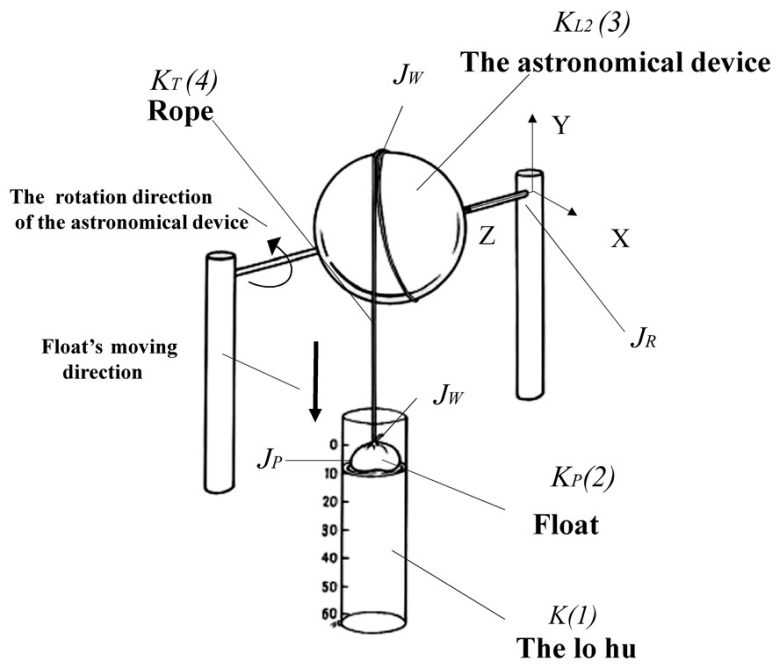

(a) Original illustration (Sarma, 2018)

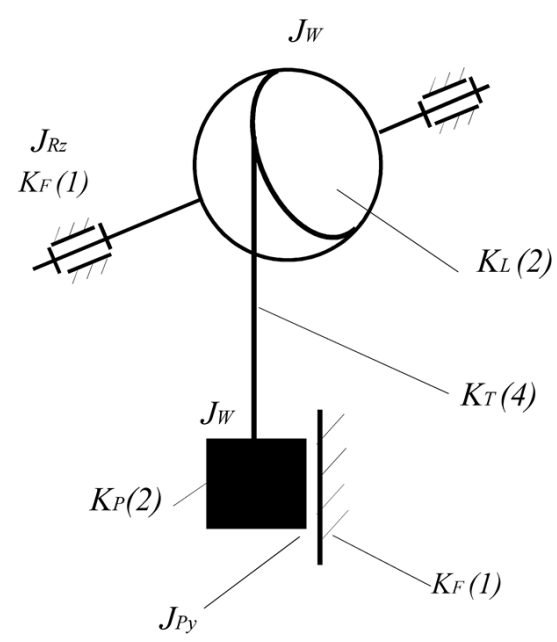

(b) Structural sketch

Figure 7. Reconstruction of Āryabhaa's self-propelled machines.

chines of the astronomer Bhāskarāchārya (1114-1185 CE) was disseminated to Europe. In addition, Siddhanta Shiromani, the major treatise of Bhāskarāchārya, recorded the design of the jala chakra yantra, a waterwheel machine that was designed using a steady-flow siphon and perpetual motion concepts (Fig. 11; Narvekar, 2005).

In the 13th century, Alfonso X of Castile's (12211284 CE) Libros del saber de astronomia (Books of wisdom of astronomy of King Alfonso $X$ of Castile) recorded a mercury wheel astronomical clock designed with a clepsydra with circular intervals. The clock's design was influenced by the concept of a perpetual motion machine put forward by an Indian mathematician (Fig. 12; Needham, 1959).
Table 1 lists the records of the power transmission systems of water-powered mechanical clocks, in chronological order, until the Middle Ages. Before the 9th century, most of the water clocks were driven by floats. Since the power transmission components of a water-powered mechanical clock relied on the float, the pot had to be changed manually to let the float to regenerate power when the float sank to the bottom of the pot. Compared to the float device, the waterwheel steelyard clepsydra device could generate a constant torque which was able to drive the mechanical clock consistently. The ancient Chinese continued to design and develop the waterwheel steelyard clepsydra devices. The floats were gradually replaced by the waterwheels after the inven- 

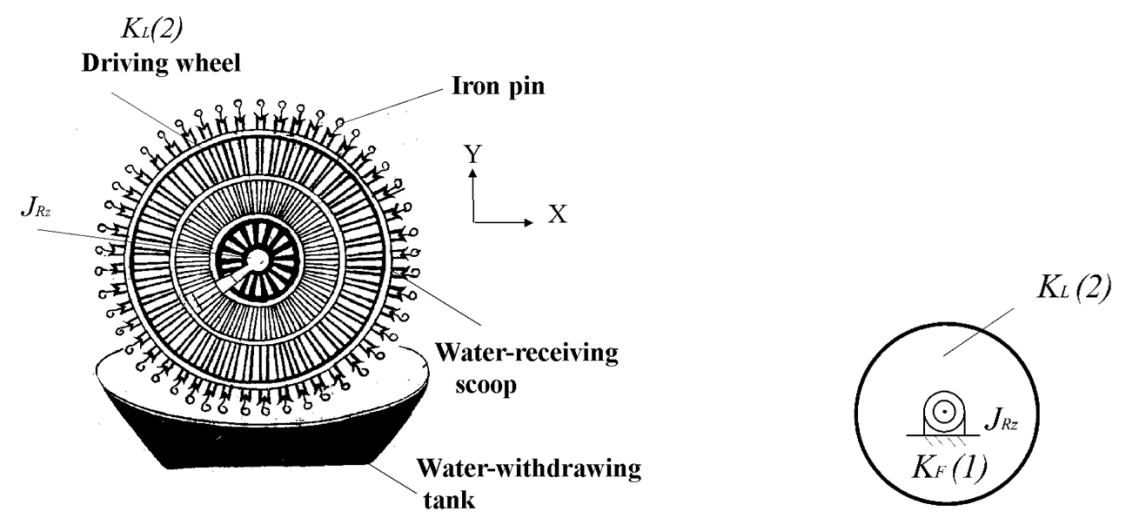

(a) Original illustration $(\mathrm{Hu}, 1997)$

(b) Structural sketch (Hsiao and Yan, 2014)

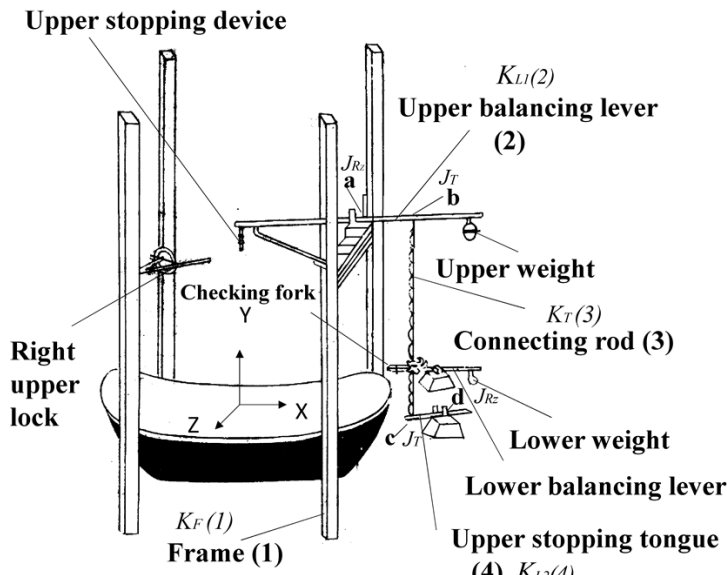

(4) $K_{L 22}(4)$

(c) Original illustration $(\mathrm{Hu}, 1997)$

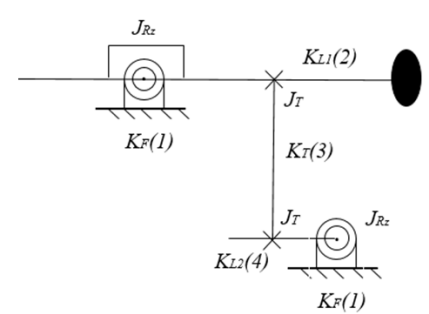

(d) Structural sketch (Hsiao and Yan, 2014)

Figure 8. Su Song's driving wheel and upper balancing lever mechanism.

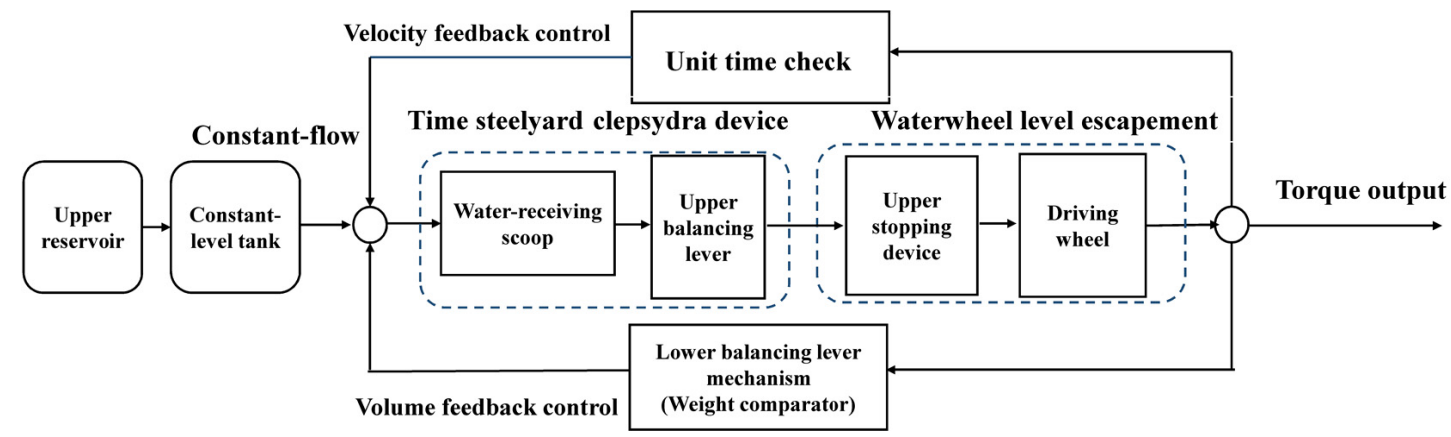

Figure 9. Kinematic model of the waterwheel steelyard clepsydra device.

tion of the multi-functional waterpower mechanical clocks in the 10th century. In addition, the waterwheels were developed into the compartmented cylindrical clepsydras, which became the power transmission devices of the Western mercury clocks after the 13th century (Bedini, 1962).

Although there are no physical objects or drawings from the past that exist today, the historian Song Lian (1310-
$1381 \mathrm{CE}$ ), who lived during the Ming dynasty, stated the following in the Volume on astronomy in his compilation Yuan shi (The history of Yuan): “... a suspended ball, the two ends of the beam are decorated with dragon heads, with the mouth open and eyes moving to assess the rising level of water... The mechanism is concealed in a cabinet and powered by water" (Song, 1976). In the accounts of Pseudo- 


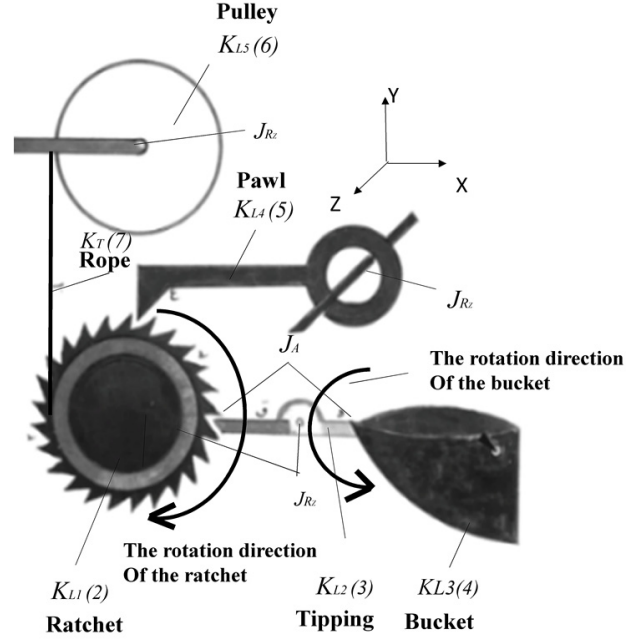

(a) Original illustration (Hill, 1973)

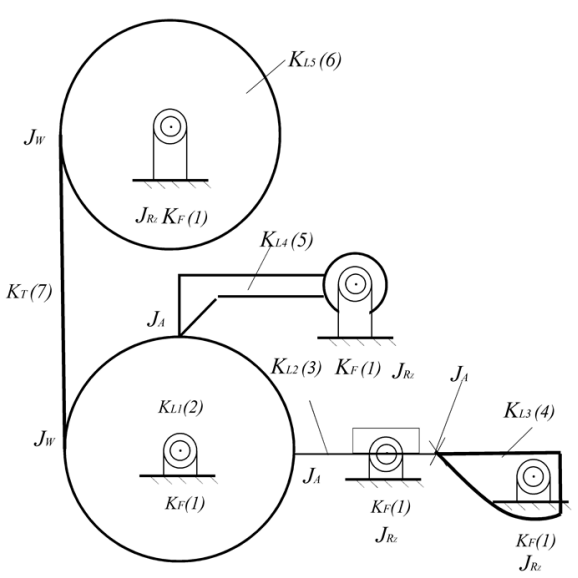

(b) Structural sketch

Figure 10. Al-Jazari's peacock tipping bucket and ratchet mechanism.

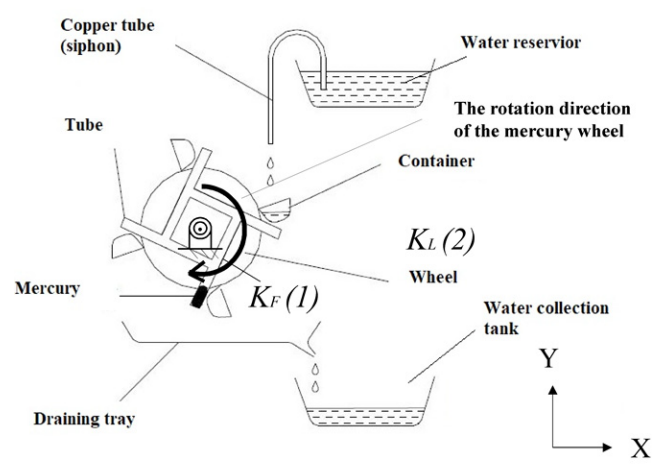

(a) Original illustration (Narvekar, 2005)

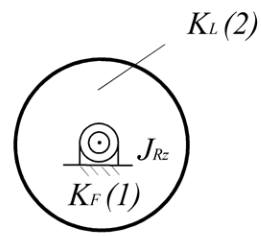

(b) Structural sketch

Figure 11. Mercury-driven water clock built by Indian mathematician Bhāskarāchārya.

Archimedes, there were descriptions similar to the mechanism described by the phrases "mouth open and eyes moving" and "the mechanism is concealed in a cabinet and powered by water". Also in Pseudo-Archimedes, there was description of a sunken float used to drive the eye movement of a wooden puppet and a description of waterwheels as a medium of transmission. Figure 13 shows a reconstruction of the original Pseudo-Archimedes design (Wellbrock, 2015). Moon-Hyon Nam believes that the ongnu (jade) clepsydra developed by the scientist Jang Yeong-sil, from the Korean Peninsula, was designed after Guo Shou Jing's da ming dian deng lou (lantern clepsydra) of the Ming dynasty (Wellbrock, 2015). The ongnu clepsydra used the waterwheel as its main driving mechanism. In addition, it was believed that the da ming dian deng lou (lantern clepsydra) built by Guo Shou Jing during the Yuan dynasty also used floats and waterwheels. However, more historical evidence is needed to support this claim.

\section{Time indicator and reporting mechanisms}

Due to different power transmission components and uses of ancient Chinese and Western water-powered mechanical clocks, different time-indicating devices and time-reporting devices were developed. The following describes the historical development of the ancient water-powered mechanical clock time indicator devices and time-reporting devices.

\subsection{Time indicator devices}

The evolution of the water clock time indicator system, including the lines of measurement marked on the inside of the vessels, qian chi (indicator arrow), hun xiang (armillary sphere), astrolabe, mechanical calendar, eyeball-colorchanging time-displaying device, time indicator and reporting mechanisms, dial indicators, and clock towers are briefly explained as follows. 


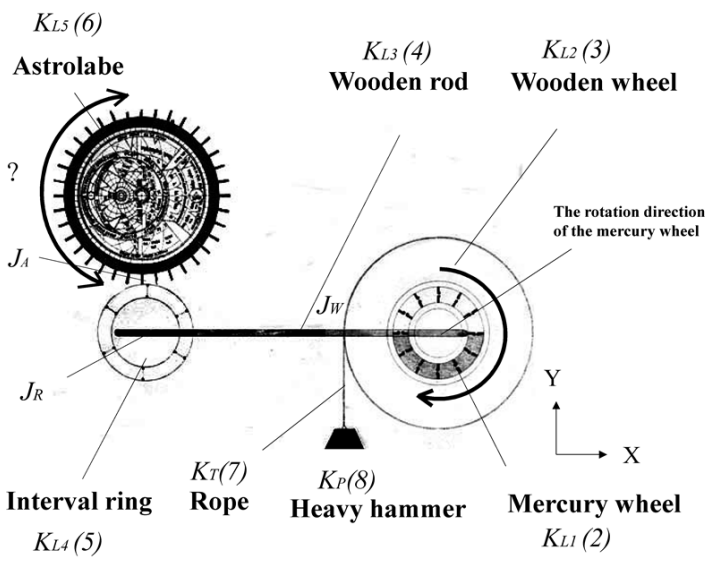

(a) Original illustration (Needham, 1959)

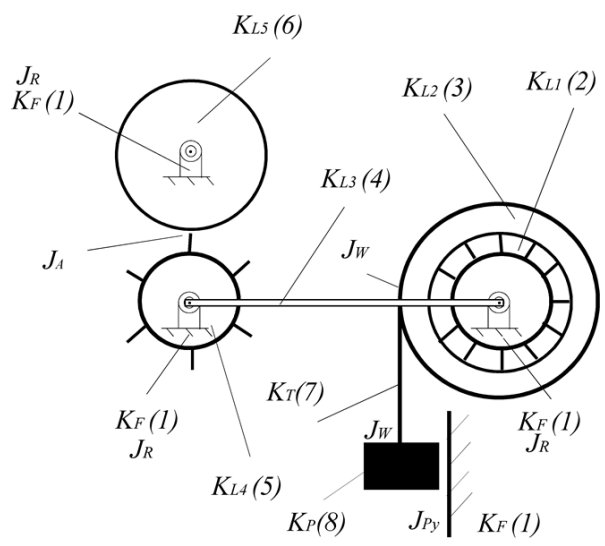

(b) Structural sketch

Figure 12. Alfonso X of Castile's mercury clock.

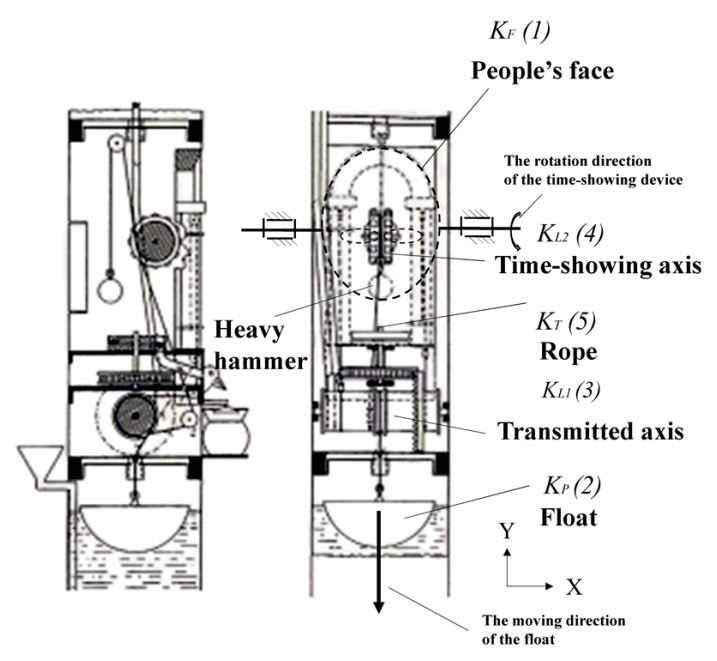

(a) Original illustration (Wellbrock, 2015)

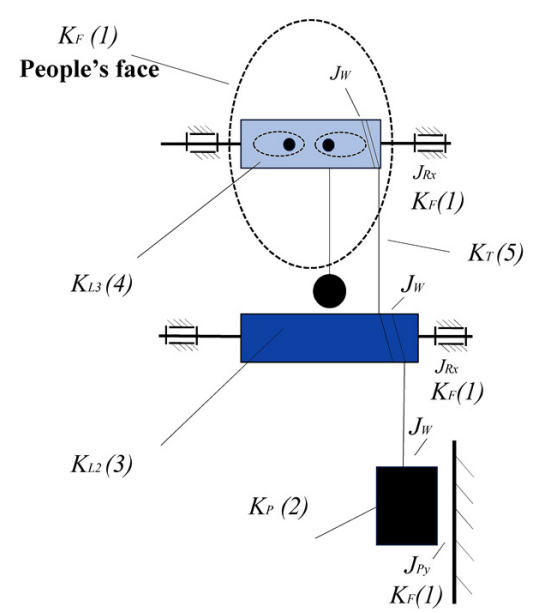

(b) Structural sketch for the face time-showing device

Figure 13. Reconstruction of Pseudo-Archimedes's water clock.

\subsubsection{Scale markings inside the clepsydra vessel and the qian chi}

In the most primitive clepsydra, the time is judged by the number of notches in the pot, such as Karnak clepsydra (1379-1342 BCE) and Agora clepsydra (about the 5th century $\mathrm{BCE})$. According to historical records, prior to the invention of the qian chi (indicator arrow), clepsydras in ancient China were used to measure time by means of a marking after each bowl had been emptied (Hua, 1991). During the Shang dynasty, after the invention of the Ke system of measurement, clepsydras indicated time using submerged qian chi, and the qian chi had to be replaced with the passage of each of the 24 lunar seasons (Wang, 2015).

\subsubsection{Hun xiang (armillary sphere), astrolabe, and mechanical calendar}

The hun xiang is used to demonstrate the movement of the celestial phenomena, mainly based on ancient China; there are few water-powered astronomical clocks in the West, which are mainly used to display astronomical devices. And there are several mechanisms, such as astrolabes and mechanical calendars, which are introduced below.

\subsubsection{Hun xiang and astrolabe}

A hun xiang (armillary sphere), also known as a hun tian $y i$, is similar to the modern day celestial globe as it shows the apparent positions of the heavenly bodies. Ancient Chinese literature recorded that Zhang Heng, during the eastern Han dynasty, built a water transport armillary sphere (Fang, 
Table 1. Power transmission systems of water-powered mechanical clocks.

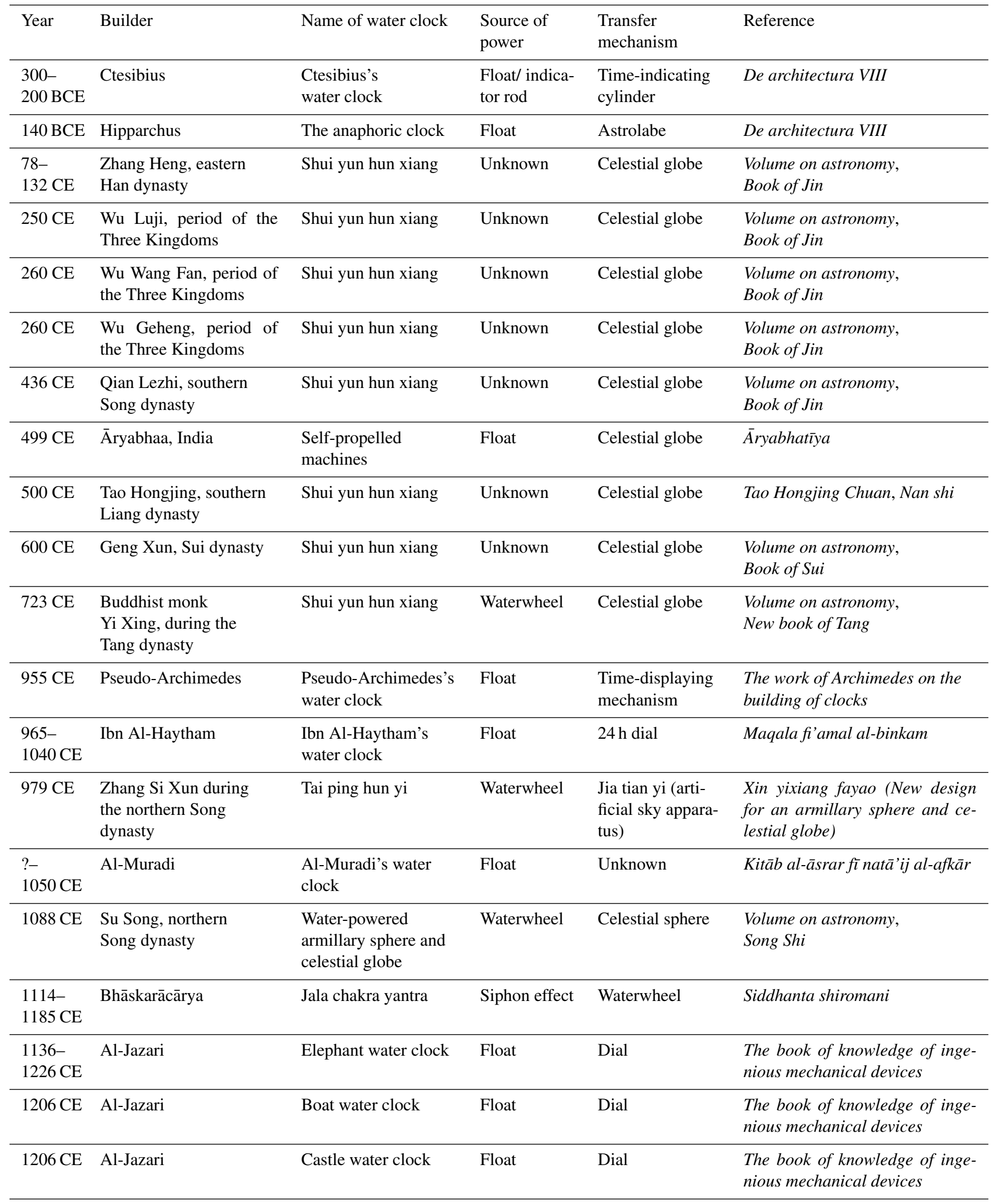


Table 1. Continued.

\begin{tabular}{|c|c|c|c|c|c|}
\hline Year & Builder & Name of water clock & $\begin{array}{l}\text { Source of } \\
\text { power }\end{array}$ & $\begin{array}{l}\text { Transfer } \\
\text { mechanism }\end{array}$ & Reference \\
\hline $1206 \mathrm{CE}$ & Al-Jazari & Breaker water clock & Float & Dial & $\begin{array}{l}\text { The book of knowledge of inge- } \\
\text { nious mechanical devices }\end{array}$ \\
\hline $1206 \mathrm{CE}$ & Al-Jazari & Drummer water clock & Float & Dial & $\begin{array}{l}\text { The book of knowledge of inge- } \\
\text { nious mechanical devices }\end{array}$ \\
\hline $\begin{array}{l}?- \\
1230 \mathrm{CE}\end{array}$ & Ridhwan Al-Sa'ati & Jayrun water clock & Float & Glass roundel & Amal al-sa'at wa'l-'amal biha \\
\hline $\begin{array}{l}1231- \\
1316 \mathrm{CE}\end{array}$ & $\begin{array}{l}\text { Guo Shoujing, Yuan } \\
\text { dynasty }\end{array}$ & $\begin{array}{l}\text { Da ming dian deng } \\
\text { lou (lantern clepsy- } \\
\text { dra) }\end{array}$ & Waterwheel & $\begin{array}{l}\text { Time-reporting } \\
\text { mechanism }\end{array}$ & $\begin{array}{l}\text { Volume on astronomy, } \\
\text { Yuan Shi }\end{array}$ \\
\hline $\begin{array}{l}1398- \\
1433 \mathrm{CE}\end{array}$ & Jang Yeong Sil & $\begin{array}{l}\text { Self-striking water } \\
\text { clock }\end{array}$ & $\begin{array}{l}\text { Floating } \\
\text { arrow type }\end{array}$ & $\begin{array}{l}\text { Self-striking } \\
\text { time-reporting } \\
\text { mechanism }\end{array}$ & $\begin{array}{l}\text { Borugakki (Record of time- } \\
\text { annunciating pavilion) }\end{array}$ \\
\hline $\begin{array}{l}1398- \\
1433 \mathrm{CE}\end{array}$ & Jang Yeong Sil & $\begin{array}{l}\text { Heumgyeonggaknu } \\
\text { (ongnu) }\end{array}$ & Waterwheel & $\begin{array}{l}\text { Time-reporting } \\
\text { mechanism and } \\
\text { astronomy } \\
\text { demonstration } \\
\text { device }\end{array}$ & Sejong sillok \\
\hline
\end{tabular}

1974). Zhang Heng was a proponent of huntian shuo (the theory of spherical heavens), which postulated that the Earth was located at the center of the cosmos. The circle of the armillary sphere was divided into two halves, with the North Pole and South Pole, haung chitao (ecliptic and equinoctial), 24 solar terms, 28 xing xiu (28 lunar mansions), zhongwai xingguan, and the Sun, Moon, and wuwei (five stars). Since then, astronomers from successive dynasties used the Sun, Moon, five stars, and the 28 lunar mansions to verify the accuracy of their calendar systems. In the hun xiang (armillary sphere), the heaven (the sky) was shaped like a sphere, with the Earth located inside the sphere, and observers could observe the positions and motion of the celestial bodies from within. This slowly rotating artificial sky was referred to as jia tian yi (artificial sky apparatus). In addition, the ancient Indian mathematician Bhāskara I (600-680 CE) had a model of the earth in the middle of the armillary sphere, which has the double rings of the Sun and the Moon (Lu, 2015). Its structure is similar to that of Wu Ge Heng (Wei et al., 1973) during the Three Kingdoms (220-280 CE) of ancient China, Qian Le Zhi in the southern Song dynasty (1127-1279 CE) (Fang, 1974), Liang Tao Hong Jing in the southern Song dynasty (Lee, 1975), and Geng Xun in the Sui Dynasty (Wei et al., 1973). In the West, the hun xiang (armillary sphere) was rarely used in water clocks for timekeeping. Self-propelled machines designed by Indian mathematician Āryabhaa used floats to drive the armillary sphere (Sarma, 2018). In addition, the treatise in Indian astronomy Surya siddhanta also contained records of water-powered armillary spheres used to indicate celestial events. The treatise De architectura contained the records of an anaphoric clock built by the Greek astronomer Hipparchus (190-120 BCE) during the kingdom of Bithynia (294-74 BCE), which used ropes and pulleys to rotate an astrolabe (Rose, 1867). Alfonso X of Castile (1221$1284 \mathrm{CE}$ ) also designed a mercury clock, which consisted of mercury-filled chambers separated by narrow partitions. The clock used a steelyard clepsydra to drive the astrolabe (Bedini, 1962).

\subsubsection{Mechanical calendar}

Historical documents show that the water-powered armillary sphere built by Zhang Heng during the eastern Han dynasty had a date-counting mechanism known as rui lun ming jia, which functioned similarly to a mechanical calendar. In ancient China, the zodiac was divided into 28 segments, representing the 28 xing xiu (lunar mansions). Each day, the Moon moves eastward to one of the 28 segments, and by observing the position of the Moon within the 28 xing xiu, 


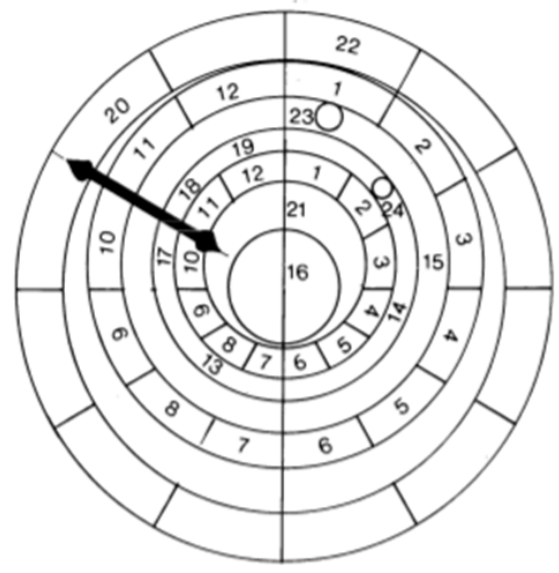

Figure 14. Castle water clock built by Al-Jazari. It included a display of the solar and lunar orbits and the phases of the Moon (Hill, 1973).

the date of the month can be determined. Records showed that, in ancient China, water-powered mechanical astronomical clocks were equipped with Sun and Moon orbits. In chronological order, ancient astronomical clocks included the water-powered armillary spheres built by Yi Xing and by Liang Lingzhan during the Tang dynasty, the Taiping armillary sphere built by Zhang Si Xun during the northern Song dynasty, the ji heng by Wang Fu (1079-1126 CE) during the northern Song dynasty, the da ming dian deng lou (lantern clepsydra) and lingta armillary sphere built by Guo Shou Jing (1231-1316 CE) in the Yuan dynasty, and the kong lou by Emperor Shun during the Yuan dynasty (1320-1370 CE). However, a further investigation of the literature is required to ascertain whether these water-powered mechanical astronomical clocks were equipped with the ability to count days. In addition, the castle water clock built by Al-Jazari also included a mechanism that simulated the positions of the Sun and the Moon in the zodiac and the phases of the Moon (Fig. 14; Hill, 1973).

\subsubsection{Indicating time at fixed intervals}

There are four main types of time-displaying devices for water-powered mechanical clocks of Arab scientists, namely a circular disc time-reporting device, a long-striped timereporting device, an eye-color-changing time-displaying device, and a puppet pointing time device.

Al-Jazari's water clock is the most used circular disc time device, along with the jayrun water clock of Ridwan al-Sa'at; among them, the long-strip time display device and the eyechanging time display device were developed around 5th century and were used in ancient Gaza markets as a waterpowered mechanical clock time-displaying device (Wellbrock, 2015). Later, the Western water-powered mechanical clock developed a circular disc time-displaying device. The puppet's pointing time device is Al-Jazari's use of floats and shots to create a mechanical balance. The sinking float drives the puppet to rotate, indicating the time on the circular hour plate; Al-Jazari's book recorded the structure of this device, which consisted of a planar mechanism with six members and seven joints with 1 degree of freedom of movement (Fig. 15; Hill, 1973).

\subsection{Time-reporting devices}

Based on ancient historical documents, the time-telling system of a water-powered mechanical clock includes a cam time-telling mechanism, metal balls for the time-telling mechanism, and air friction to make a sound. The brief introduction is as follows.

\subsubsection{Cam mechanisms}

The wooden man timekeeping mechanism of the waterpowered mechanical clock appears to be an application of the cam mechanism. Mu Jun of the Three Kingdoms (220$226 \mathrm{CE}$ ) used the waterwheel and water turret to drive the wooden figure as a mechanical toy. Needham (1900$1995 \mathrm{CE}$ ) believed that the wooden man time-telling mechanism of Yi Xing and Liang Lingzhan's water transportation were both driven by Ma Jun's water transfer mechanism (Needham, 1965). Therefore, it can be concluded that the time-telling mechanism of the water-powered mechanical clock after the Tang dynasty (618-907 CE) adopts the cam mechanism as the design. Besides, Al-Jazari's castle clock uses a cam mechanism to trigger a wooden man to beat the drums every 6, 9, and $12 \mathrm{~h}$ (Hill, 1973).

\subsubsection{Metal balls for time-telling mechanism}

This method of timekeeping was the most common in the Song dynasty. In ancient China, there were several kinds of time-reporting mechanisms used in water clocks. According to historical records, i.e., volume 198 of Jiu Tangshu (The Old book of Tang; 888-947 CE) contained the following description: "Inside the second door, there hangs a huge golden scale. [A total of] 12 golden balls are attached to the horizontal lever, each representing one of the $122 \mathrm{~h}$ periods of the day. There is a golden puppet, tall as a person, standing on the side. [At] every $2 \mathrm{~h}$ period, the puppet will drop a golden ball and make a sound." This method of timekeeping was the most common for water clocks in the Song dynasty.

Historical records using this method of water-powered mechanical clocks are the lou ke of Cheng Shi Meng (1009$1086 \mathrm{CE}$ ) in the northern Song dynasty, the lian hua lou (lotus clepsydra) of Han Zhong Tong of the northern Song dynasty (Hua, 1991), and the da ming dian deng lou (lantern clepsydra) of Guo Shou Jing (1231-1316 CE) of the Yuan dynasty.

The West used this method to tell the time around the 9th century, and the Falcon telling device of the water-powered 


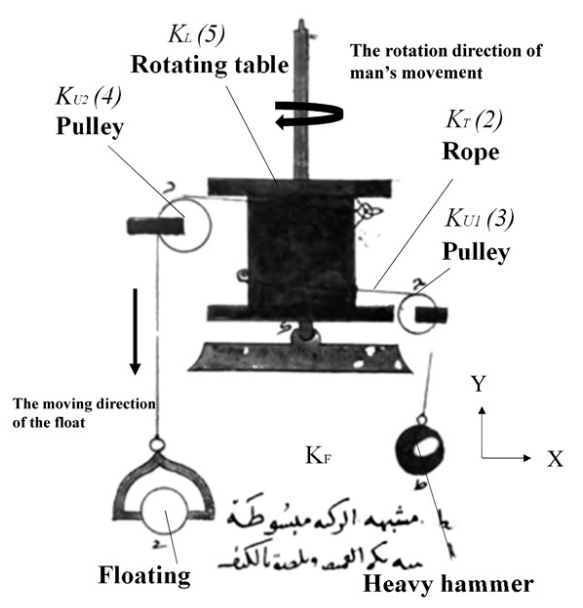

(a) Original illustration (Hill, 1973)

Figure 15. Al-Jazari’s puppet pointing time device.

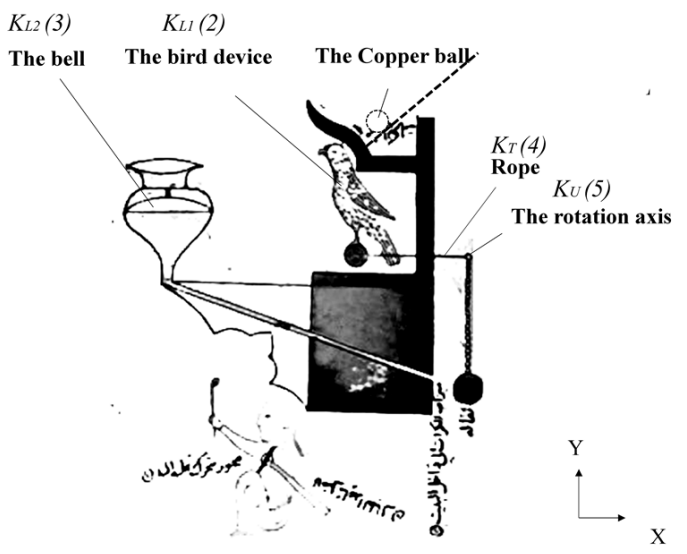

(a) Original illustration (Hill, 1973)

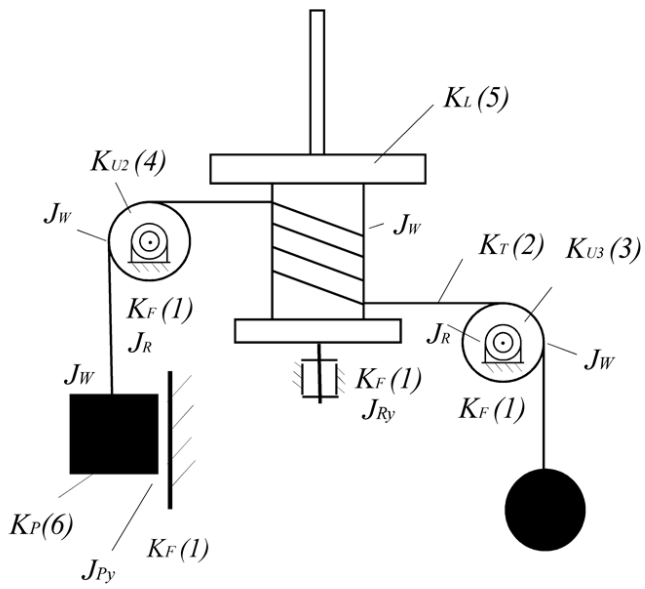

(b) Structural sketch

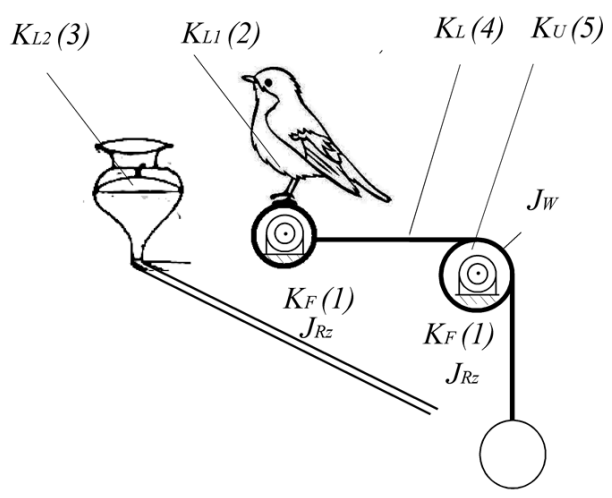

(b) Structural sketch

Figure 16. Al-Jazari's falcon time-reporting device.

mechanical clock of Al-Jazari also used this kind of timereporting device (Fig. 16; Hill, 1973).

During the Joseon dynasty (1392-1897 CE), the striking palace clepsydra (jagyeok-gung-nu) developed by Jiang Young Sil (1383-1450 CE) also used a copper ball to trigger the 12 shi chen (equal to $2 \mathrm{~h}$ ) magical time device (Fig. 17; Nam, 2014).

Moon-Hyon Nam believes that, during the Goryeo dynasty, water clock mechanisms that used bells, drums, and cymbals, as well metal balls to move puppets to report time, were all imported from ancient China and from Muslim civilizations (Nam, 1995).

\subsubsection{Whistling sound from air forced through small openings}

This method of time reporting is to use the sound of the friction between water and air in a closed container to tell time. It originated from the alarm clock of the ancient Greek philosopher Plato (429-347 BCE). Al-Jazari most often designed this device as a method of time reporting in his waterpowered mechanical clocks (Russell, 2018).

\subsubsection{Time-telling tower}

Time-telling clock towers first appeared in China during the Sui dynasty (581-619 CE), where the water-powered mechanical clocks were built and looked like clock towers. In the Volume of astronomy in the History of Song, the historian Tuotuo (1314-1356 CE), during the Yuan dynasty, described the tai ping hun yi built by Zhang Si Xun during the northern Song dynasty. Xin yi xiang fa yao (New design for an armillary sphere and celestial globe; 1094-1096 CE), compiled by $\mathrm{Su}$ Song during the northern Song dynasty, also contained descriptions of a shui yun yi xiang tai, or water-powered armillary sphere and celestial globe (Fig. 18; Hu, 1997). 


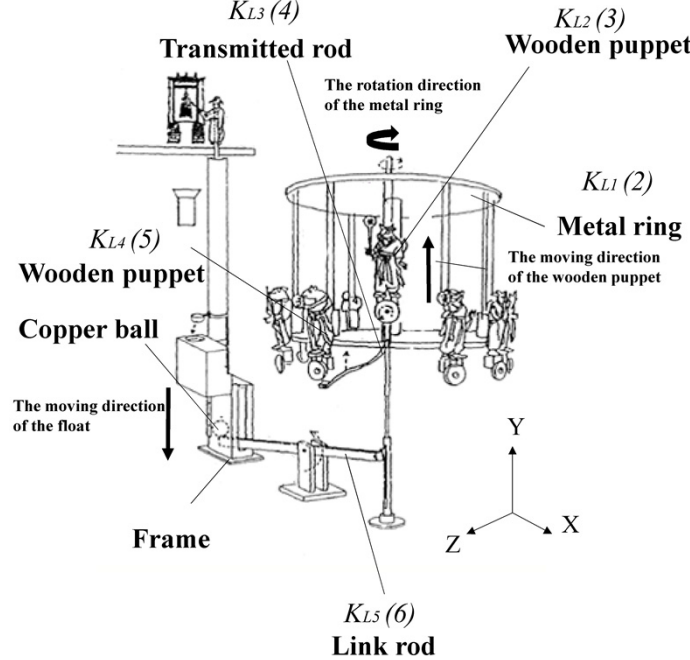

(a) Original illustration (Nam, 2014)

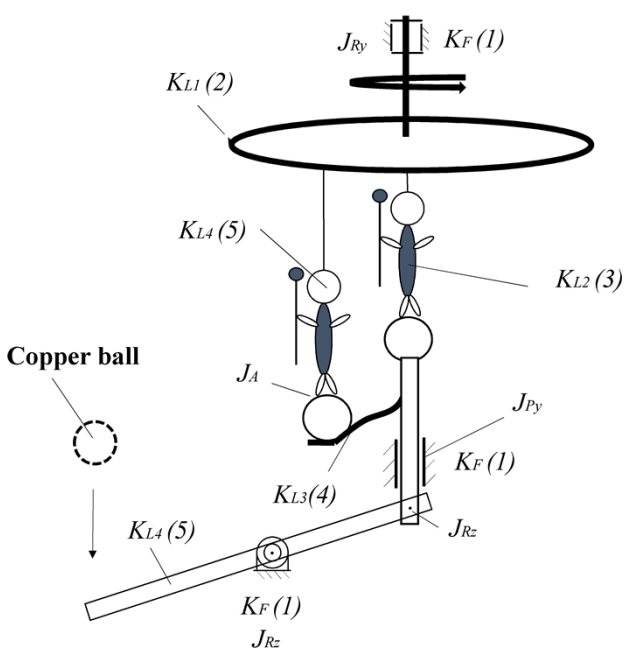

(b) Structural sketch

Figure 17. Jiang Ying Shi's 12 h God device.

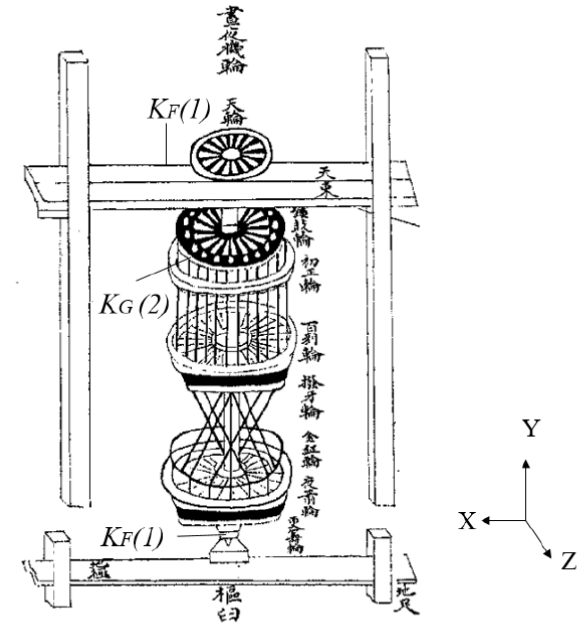

(a) Original internal structure illustration $(\mathrm{Hu}, 1997)$

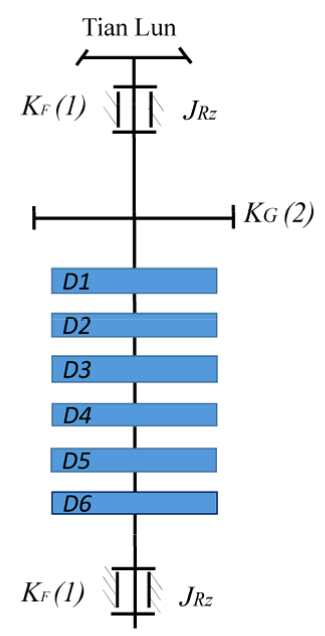

(b) Internal structural sketch

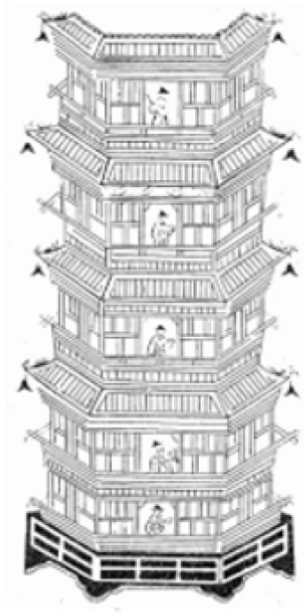

(c) External structural sketch (Hu, 1997)

Figure 18. Time-telling wooden pagoda of the Xin yi xiang fa yao (New design for an armillary sphere and celestial globe).

\section{Conclusions}

After the invention of the feedback system in water clocks, the mechanization of the ancient water clock began. Waterpowered mechanical clocks in ancient China were used in astronomical observations, and most were water-powered. In the West, water-powered mechanical clocks were used to display and report time. Because early records of ancient waterpowered mechanical clocks were brief and the information scattered and difficult to collect, this study analyses and compares available records on the different types of ancient clepsydra, their use and development, and the development of their feedback systems, power systems, and time-reporting systems to better understand the historical development of the power drive components, feedback system application, time-reporting mechanism design, and astronomical devices of ancient Chinese and Western water-powered mechanical clocks. In addition, the invention of a waterwheel with timing function led to the development of a waterwheel steelyard clepsydra device in ancient China. The transmission system of water-powered mechanical clocks was replaced by gears instead of rope hammers. The change also made the timereporting function of mechanical clocks more powerful, and subsequently led to the development of water-powered mechanical clocks with multiple functional devices for reporting time. The Western mechanical clocks powered by waterwheels with a timing function still used rope pulleys as their transmission system. The circularly spaced clepsydra mer- 
cury wheel was later developed, which became the new driving element of the Western water-powered mechanical clock after the 13th century.

During Yuan dynasty (1271-1368 CE), ancient China was influenced by the introduction of scientific and technological knowledge from western Asia. The water-powered mechanical clocks of Guo Shou Jing of Yuan dynasty and Emperor Shun of the Yuan dynasty gradually deviated from the shape of ancient Chinese traditional astronomical clocks and developed new styles of water-powered machinery. It is hoped that this study can provide scholars with a valuable reference for the systematic reconstructions of water-powered mechanical clocks.

Data availability. The data are available upon request from the corresponding author.

Author contributions. ZHH is the lead author of this article. He was responsible for collecting the research literature, organizing the paper structure, and writing the paper. HSY and TYL provided the research direction of this paper, together with suggestions for the revision and correction of the paper.

Competing interests. The authors declare that they have no conflict of interest.

Acknowledgements. The authors are grateful to the Ministry of Science and Technology (Taiwan, ROC; grant no. MOST 106-2221E-006-100-MY3) for the financial support for this work.

Financial support. This research has been supported by the Ministry of Science and Technology, Taiwan (grant no. MOST 1062221-E-006-100-MY3).

Review statement. This paper was edited by Dongming Gan and reviewed by two anonymous referees.

\section{References}

Anettle, S.: The Karnak Clepsydra and its Successors, Water Management in Ancient Civilizations, 53, 321-346, 2018.

Aubriot, O.: The timekeeper, Archives-Ouvertes, 24, 2018.

Bedini, S.: The Compartmented Cylindrical Clepsydra, Technol. Cult., 3, 151-141, 1962.

Bonine, M.-E.: From Qanātto Kort: Traditional Irrigation Terminology and Practices in Central Iran, J. Brit. Inst. Persian Studies, 20, 145-159, 1982.

Breasted, J.-H.: The Beginnings of Time-Measurement and the Origins of Our Calendar, Sci. Mon., 41, 289-304, 1935.
Brown, D., Fermor, J., and Walker, C.: The water clock in Mesopotamia, Archive for Oriental Studies, 46, 130-148, 1999.

Buick, T.: Orrery: A Story of Mechanical Solar Systems, Clocks, and English Nobility, Springer, New York, USA, 2014.

Ceccarelli, M. and Koetsier, T.: Explorations in the History of Machines and Mechanisms, Springer, New York, USA, 2007.

Chen, M.-T. and Hua, T.-X.: Zhong Guo Zi Shi Yi Qi Tong Shi, Anhui Jiaoyu Chubanshe, Anhui, China, 2007 (in Chinese).

Chen, M.-L.: Gu Jin Tu Shu Ji Cheng, Zhong Hua Book Company, Shanghai, China, 1934 (in Chinese).

Drachmann, A.-G.: Ktesibios's Water Clock and Heron's Adjustable Siphon, Centaurus, 20, 1-10, 1976.

Ebiesuwa, O.-O., Adekunle, Y., and Akinyemi, L.: Line Follower Robot Using a Sophisticated Sensor Approach, Int. J. Eng. Res. Technol., 1.02, 1980-1982, 2013.

Fang, X.-L.: (Tang Dynasty): Jin Shu, Zhong Hua Book Company, Beijing, China, 1974 (in Chinese).

Goodenow, J., Orr, R., and Ross, D.: Mathematical Models of Water Clocks, Rochester Institute of Technology, New York, USA, 2015.

Han, Z.-H.: Hang Hai Jiao Tong Mao Yi Yan Jiu, Center of Asian Studies of Hong Kong, Hong Kong, China, 2002 (in Chinese).

Hill, D.-R.: The Book of Knowledge of Ingenious Mechanical Devices: (Kitāb fī ma'rifat al-iyal al-handasiyya), D. Reidel Publishing Company, Boston, USA, 1973.

Hsiao, K.-H. and Yan, H.-S.: Mechanisms in Ancient Chinese Books with Illustrations, Springer, Cham, Switzerland, 2014.

Hu, W. J.: Xin Yi Xiang Fa Yao: A Modern Interpretation, Liaoning Jiaoyu Chubanshe, Shenyang, China, 1997 (in Chinese).

Hua, T.: Zhong Guo Lou Ke, Science and Technology Press, Anhui, China, 1991 (in Chinese).

James, P. and Thorpe, N.: Ancient Inventions, The Ballantine Publishing Group, New York, USA, 1995.

Ker, J.: Drinking From the Water-Clock: Time and Speech in Imperial Rome, Arethusa, 42, 279-302, 2009.

Lee, Y.-S.: (Tang Dynasty) Nan Shi-Tao Hong Jing, Chuan, Zhong Hua Book Company, Beijing, China, 1975 (in Chinese).

Lin, T.-Y.: A Systematic Reconstruction Design of Ancient Chinese Escapement Regulators, PhD thesis, National Cheng Kung University, Tainan, Taiwan, 2001 (in Chinese).

Liu, X., Zhang, Z., and Jia, W.: : (Later Jin Dynasty), Jiu Tang Shu (in Chinese), Ding Wen Publishing House, Taipei, Taiwan, 1981.

Lu, P.: Bhāskara I on the Construction of the Armillary Sphere, Hist. Sci. South Asia, 3, 1-19, 2015.

Mayr, O.: The origins of feedback control, M.I.T Press, Cambridge, UK, 1969.

McNown, J.-S.: When time flowed the story of the clepsydra, La Houille Blanche, 5, 347-353, https://doi.org/10.1051/lhb/1976021, 1976.

Nam, M.-H.: A Technical Survey on the Astronomical and Timekeeping Instrument Made during the King Sejong's Reign, Studies in the History of Natural Sciences, 14, 42-50, 1995.

Nam, M.-H.: Yeong Sil Jang (Unknown) in Distinguished Figures in Mechanism and Machine Science, Springer, Singapore, 2014.

Narvekar, S.-R.: Constant RPM water wheel clock, 12th National Conference on Machines and Mechanisms, 36, North Guwahati, India, 2005.

Needham, J. F. R. S.: The Missing Link in Horological History: a Chinese Contribution, P. Roy. Soc., 250, 147-179, 1959. 
Needham, J.: Science and Civilization in China, Vol. 4, Part II, Cambridge University Press, Cambridge, UK, 1965.

Neugebauer, O.: Studies in Ancient Astronomy. VIII. The Water Clock in Babylonian Astronomy, J. Hist. Sci. Soc., 37, 37-43, 1947.

Noble. V. and de Solla Price, D.-J.: The water clock in the tower of the winds, Am. J. Archaeol., 72, 345-355, 1968.

Panou, E., Theodossiou, E., Manimanis,V., and Kalachanis, K.: The astronomical monument of Athens, Global Journal of Multidisciplinary and Applied Sciences, 2, 47-52, 2014.

Pearce, J. M.-S.: The neuroantomy of Herophilus, Europen neurology, Eur. Neurol., 69, 292-295, 1939.

Ritner, K.-R.: Oriental Institute Museum Notes 16: Two Egyptian Clepsydrae (OIM E16875 and A7125), Journal of Near Eastern Studies, 75, 361-389, 2016.

Pogo, A.: Egyptian water clocks, J. Hist. Sci. Soc., 25, 403-425, 1936.

Rose, V.: De architectura, Teubneri, Germany 1867.

Russell, M.: Plato's Alarm Clock: And Other Amazing Ancient Inventions, Michael O'Mara, London, UK, 2018.

Sarma, S.-R.: Indian Astronomical and Time-Measuring Instruments, A catalogue in preparation, Ind. J. Hist. Sci., 29, 507-528, 1994.

Sarma, S.-R.: Water Clock and Steelyard in the Jyotiskarandaka, Int. J. Jaina Stud., 14, 1-49, 2018.

Schmidt, W.: Herons von Alexandria Druckwerke und Automatentheater = Pneumatica et automata, Teubner, Lipsiae (New York), USA, 1899 (in German and Greek).

Sleeswyk, A.-W. and Hulden, B.: The three water clocks described by Vitruvius, Int. J. Hist. Tech., 8, 25-50, 1991.

Sloley, R.-W.: Methods of Measuring Time: With Special Reference to Egypt, J. Egypt. Archaeol., 17, 166-178, 1993.
Song, L.: (Ming Dynasty): Yuan Shi, Zhong Hua Book Company, Beijing, China, 1976 (in Chinese).

Sridhar, S. and Shivakumar, N.: A Note on Leading Mathematician Bhaskara II of 12th Century, Int. J. Inf. Tech. Decis., 2, 788-792, 2014.

Vodolazhskaya, L.-N., Usachuk, A.-N., and Nevsky, M.-Y.: Astronomical Interpretation of the Signs on the Vessel of the Bronze Age (Central Donbass), Archaeoastronomy and Ancient Technologies, 3, 43-60, 2015.

Wang, X.-H.: Why Were the Scale-Rulers of Clepsydra Regularly Replaced? Journal of Dialectics of Nature, 2, 14, 2015.

Wei, Z., et al.: (Tang Dynasty): Sui Shu, Zhong Hua Book Company, Beijing, China, 1973 (in Chinese).

Wellbrock, K.: Cura aquarum in Greece, Proceedings of the 16th International Conference on the History of Water Management and Hydraulic Engineering in the Mediterranean region, 29 March 2015, Athens, Greece, 27, 301-334, 2015.

Woodcroft, B.: The Pneumatics of Hero of Alexandria: From the Original Greek, Charles Whittingham, London, UK, 1851.

Xu, J., Zhang, S., and Wei, S.: (Tang Dynasty): Chu Xue Ji, Ding Wen Publishing House, Taipei, Taiwan, 1976 (in Chinese).

Xu, Z.-W.: Xi Tong Hua Ke Lou Ji Shu Se Jiaocue Yu Yan Jiu, Master thesis, Southern Taiwan University of Science and Technology, Tainan, Taiwan, 2015 (in Chinese).

Young, S.: An Athenian clepsydra, American School of Classical Studies at Athens, 18, 274-284, 1939.

Zou, X.-L.: Ji Chu Han Zi Xing Yi Shi Yuan (Shuo Wen) Bu Shou Jin Du Ben Yi (revised version), Zhong Hua Book Company, Anhui, China, 2007 (in Chinese). 